\title{
Adubação mineral com cobalto e molibdênio na cultura da soja
}

\section{Mineral fertilizer with cobalt and molybdenum in soybean}

\author{
Durval Dourado Neto ${ }^{1}$; Geraldo José Aparecido Dario ${ }^{1}$; Thomas Newton Martin ${ }^{2 *}$; \\ Marciela Rodrigues da Silva ${ }^{3}$; Paulo Sergio Pavinato ${ }^{4}$; Tiago Luiz Habitzreiter ${ }^{5}$
}

\begin{abstract}
Resumo
Altas produtividades de soja requerem grandes quantidades de nitrogênio, que podem ser obtidas principalmente, a partir da fixação simbiótica. No entanto, há possibilidade da eficiência desse processo biológico ser prejudicada pela deficiência de micronutrientes, especialmente de cobalto e molibdênio. Nesse contexto, objetivou-se com o presente trabalho avaliar a eficiência agronômica e a forma de aplicação de adubação mineral com cobalto e molibdênio na cultura da soja. Para tanto, a cultivar CD-206 foi submetida a diferentes tratamentos que consistiram da combinação entre aplicação de Co e Mo via tratamento de sementes e adubação foliar. As características agronômicas avaliadas foram o número de nódulos, massa seca da parte aérea, massa seca de raiz, número de vagens, número de grãos, massa de mil grãos e produção de grãos. A aplicação de molibdênio e cobalto via sementes e/ ou adubação foliar no estádio V4 (terceira folha trifoliolada completamente desenvolvida, quarto nó) promoveram incrementos significativos no rendimento da cultura. Respostas positivas ao cobalto e molibdênio também foram observadas no número de nódulos, vagens e grãos, com aumentos de até 240 $\mathrm{kg} \mathrm{ha}^{-1}$ no rendimento da cultura. Os parâmetros agronômicos avaliados foram afetados positivamente pela aplicação de Co e Mo, principalmente quanto aplicado tanto via semente como foliar (TS + V4), inclusive para a produtividade de grãos. A forma de aplicação não foi significativamente distinta, ou seja, tanto a aplicação via semente como via foliar foram eficientes no fornecimento destes nutrientes para a cultura da soja.
\end{abstract}

Palavras-chave: Glycine Max (L.) Merrill, adubação foliar, molibdênio, cobalto

\begin{abstract}
High soybean yields require large amounts of nitrogen, which can be obtained mainly from symbiotic fixation. However, the possibility of the efficiency of this biological process cam be impaired by micronutrient deficiencies, especially of cobalt and molybdenum. In this context, the objective of this study was to evaluate the agronomic efficiency and application form of mineral fertilizer with cobalt and molybdenum in soybean. To do so, the cultivar CD-206 was subjected to different treatments which consisted of the combination of Co and Mo application as seed treatment and as leaf application. The agronomic characteristics evaluated were nodule number, shoot dry mass, root dry mass, number of pods, number of grains, thousand grain weight and grain production. The application of molybdenum and cobalt via seeds and/or leaf application in V4 stage (third trifoliolate leaf fully developed, fourth node) promoted significant increases in crop yield. Positive responses of molybdenum and cobalt were
\end{abstract}

\footnotetext{
${ }^{1}$ Profs. do Dept ${ }^{o}$ de Produção Vegetal, Escola Superior de Agricultura “Luiz de Queiroz”, Universidade de São Paulo, Piracicaba, SP. E-mail: dourado@esalq.usp.br; gjadario@esalq.usp.br

${ }^{2}$ Prof. do Dept ${ }^{\mathrm{o}}$ de Fitotecnia, Centro de Ciências Rurais, Universidade Federal de Santa Maria, Camobi, E-mail: martin.ufsm@ gmail.com

${ }^{3}$ Mestranda do programa de Pós Graduação em Agronomia da Universidade Tecnológica Federal do Paraná, UTFPR, Pato Branco, PR. E-mail: marciela-rodrigues@hotmail.com

${ }^{4}$ Prof. do Dept ${ }^{0}$ de Ciência do Solo, Escola Superior de Agricultura “Luiz de Queiroz”, USP, Piracicaba, SP. E-mail: pavinato@usp.br

${ }^{5}$ Discente de Graduação da UTFPR, Dois Vizinhos, PR. E-mail: tyagoluys@hotmail.com

* Autor para correspondência
} 
also observed in the number of nodes, pods and grains, with increases of up to $240 \mathrm{~kg} \mathrm{ha}^{-1}$ in crop yield. The agronomic parameters were positively affected by the application of Co and Mo, especially as applied either via seed and leaf (TS + V4), including the grain yield. The application form was not significantly different, both the application via foliar and seed were effective in delivering these nutrients to the crop.

Key words: Glycine Max (L.) Merrill, foliar fertilization, molybdenum, cobalt

\section{Introdução}

O Brasil é o segundo maior produtor mundial de soja, com uma área plantada de aproximadamente 23,6 milhões de hectares, e um volume de produção que corresponde a mais de $44 \%$ do total de grãos produzidos no país (CONAB, 2010). A produtividade dessa leguminosa considerando a sua capacidade genética é elevada, porém a disponibilidade de nutrientes associada a fatores climáticos é ainda o que mais limita o seu rendimento.

A adubação é um fator determinante da produtividade e representa um percentual significativo no custo de produção da cultura. Em função disso, seu cultivo se torna mais viável economicamente pela capacidade de fixação biológica do nitrogênio que esta cultura apresenta. Caso contrário, seriam necessários aproximadamente $240 \mathrm{~kg} \mathrm{ha}^{-1}$ de $\mathrm{N}$ para uma produção esperada de grão de $3.000 \mathrm{~kg} \mathrm{ha}^{-1}$, o que causaria aumento expressivo no custo de produção (HUNGRIA; CAMPO; MENDES, 2001).

Entretanto, a eficiência do processo de fixação biológica pode ser prejudicada pela deficiência de micronutrientes, principalmente cobalto (Co) e molibdênio (Mo). Autores como Brandelero, Peixoto e Ralisch (2009), indicam que mais de $40 \%$ do rendimento de grão se correlacionaram com os componentes da nodulação dos cultivares de soja. O molibdênio atua como um dos catalisadores da enzima nitrogenase, responsável pela transformação do $\mathrm{N}_{2}$ atmosférico em $\mathrm{NH}_{3}$. Esse nutriente também faz parte da enzima redutase de nitrato, que catalisa a redução de $\mathrm{NO}_{3}^{-}$a $\mathrm{NO}_{2}^{-}$(LANTMANN, 2002, MENGEL; KIRKBY, 2001). Da mesma forma, o cobalto é necessário para a síntese da cobalamina (Vitamina B12), que participa dos passos metabólicos para a formação da leghemoglobina, e regula sua concentração nos nódulos impedindo a inativação da enzima nitrogenase (MENGEL; KIRKBY, 2001).

Normalmente, solos que apresentam alta fertilidade possuem a capacidade de fornecer os micronutrientes necessários para cultura da soja. No entanto, o cultivo sucessivo e o manejo inadequado dos nutrientes têm ocasionado reduções nos teores de matéria orgânica e aumento da acidez (BALÍK et al., 2006). Em razão disso, tem ocorrido deficiência de alguns micronutrientes essenciais e, consequentemente, redução do processo de fixação simbiótica do nitrogênio. Até recentemente, a necessidade de adubação com micronutrientes no Brasil estava restrita à região do Cerrado, onde os solos, principalmente Latossolos e Argissolos (ADÁMOLI et al., 1986), são de baixa disponibilidade de nutrientes e altamente ácidos. Contudo, o cultivo da soja ao longo dos anos resultou na diminuição da disponibilidade de alguns micronutrientes em todos os solos do Brasil e agora é comum observar-se que a produtividade de grãos geralmente responde positivamente à adubação com micronutrientes (CAMPO; LANTMANN, 1998; CERETTA et al., 2005; SFREDO; OLIVEIRA, 2010).

A deficiência de molibdênio e cobalto na soja e nas demais culturas está se acentuando nos últimos anos. Provavelmente em função da exportação destes nutrientes pelas culturas na forma de grãos, fibras, colmos e demais produtos agrícolas, o que resultaria em diminuição da sua disponibilidade nos solos cultivados com soja e com as demais culturas. Cerca de $70 \%$ do molibdênio absorvido pela soja é exportado pelos grãos (OLIVEIRA et al., 2007). Dessa forma, à medida que a agricultura se 
intensifica e as produtividades aumentam, verificase uma importância crescente da adubação mineral com estes elementos, sendo necessário definir padrões seguros para quantificar as necessidades da cultura da soja.

As formas de aplicação de molibdênio e cobalto na soja podem ter interferência no melhor aproveitamento destes nutrientes pela cultura. A aplicação de Mo via foliar, antes do início da floração da soja é uma boa alternativa, mas como a quantidade de Mo requerida pela soja é relativamente pequena, a sua aplicação poderá ser via semente. A aplicação de Mo e Co nas sementes poderá, em função de $\mathrm{pH}$, da salinidade e da ação bactericida para o Bradyrhizobium de alguns produtos, reduzir a sobrevivência da bactéria (SILVA et al., 2011). Nesse caso, a aplicação por pulverização foliar poderia ser mais eficiente.

A resposta da cultura da soja à aplicação via semente e foliar de Co e Mo têm sido variáveis. Resultados de pesquisas não têm observado aumentos significativos no rendimento de grãos (CAMPOS; GNATTA, 2006; GRIS; CASTRO; OLIVEIRA, 2005). Entretanto, outros trabalhos tiveram resposta significativa na produtividade de grãos (CERETTA et al., 2005) com a combinação da aplicação de metade da dose na semente e metade via foliar.

A disponibilidade de produtos comerciais contendo micronutrientes tem aumentado nos últimos anos, e existem resultados experimentais mostrando grande variabilidade de resposta à sua aplicação (CERETTA et al., 2005). Dessa forma, objetivou-se com o trabalho avaliar a eficiência agronômica e a forma de aplicação de cobalto e molibdênio na cultura da soja.

\section{Material e Métodos}

O experimento foi realizado na Estação Experimental da Bayer CropScience Ltda., localizada no bairro Rhodia, município de
Paulínia, São Paulo. O solo foi classificado como Latossolo Vermelho Distroférrico de textura argilosa (EMBRAPA, 1999), com 3,1\% de matéria orgânica e $\mathrm{pH}$ em $\mathrm{CaCl}_{2}$ de 4,4, o terreno possui topografia plana e altitude média de $600 \mathrm{~m}$. O clima predominante, segundo a classificação de Köppen, é do tipo tropical de altitude (Cwa) (CEPAGRI, 2010).

O experimento foi realizado com a cultivar CD206, que possui hábito de crescimento determinado, flores roxas, pubescência marrom e sementes com hilo preto. A semeadura foi realizada no dia 31 de dezembro de 2004, na densidade de 20 (vinte) sementes por metro quadrado $(50 \mathrm{~kg}$ de sementes $\left.\mathrm{ha}^{-1}\right)$, com a emergência ocorrendo quatro dias após (04 de janeiro de 2005). Realizou-se a adubação de base seguindo-se as orientações do laudo de análise do solo, sendo aplicado o equivalente a $400 \mathrm{~kg} \mathrm{ha}^{-1}$ da fórmula 04-14-08 (RAIJ et al., 1996).

As sementes foram tratadas com o fungicida Carbendazim + Thiram na dosagem de $30+70 \mathrm{~g}$ de i.a. para cada $100 \mathrm{~kg}$ de sementes, respectivamente. Foram realizadas duas pulverizações (16/02/2005 e 07/03/2005), com o fungicida Tebuconazole, na dose de 150 g i.a. ha ${ }^{-1}$. Para o controle das pragas comuns a cultura realizou-se quatro pulverizações com o inseticida Methamidophos, na dose de 300,00 g i.a. ha-1. As plantas daninhas foram controladas por meio da aplicação em pré-emergência da mistura de herbicidas a base de Diclosulam + Trifluralin, nas doses de $2 \mathrm{~L}+1.200 \mathrm{~g}$ do i.a ha-1, respectivamente. Os tratamentos consistiram na aplicação de produtos comerciais à base de cobalto e molibdênio, na seguinte constituição e forma de aplicação, conforme Tabela 1.

O delineamento experimental utilizado foi o de blocos completamente casualizados (oito tratamentos) com quatro repetições. As parcelas experimentais foram constituídas por sete fileiras com 7,0 $\mathrm{m}$ de comprimento, espaçadas de 0,50 $\mathrm{m}$, apresentando área de $24,50 \mathrm{~m}^{2}$, resultando em uma população de 200.000 plantas por hectare. As 
análises estatísticas foram realizadas com o software Genes (CRUZ, 2006) aplicando-se a análise de variância e posteriormente para as características que apresentaram significância, aplicou-se o teste de Tukey, comparando-se as médias entre si. Utilizou-se o teste de Scheffé, para testar a forma de aplicação (em TS, aplicação foliar em V4 ou TS + V4) de modo a formar os seguintes contrastes (i) testemunha vs tratamentos com aplicação de CoMo; (ii) tratamentos com aplicação de CoMo em TS vs tratamentos com aplicação de CoMo em V4; (iii) tratamentos com aplicação de CoMo em TS vs tratamentos com aplicação de CoMo em TS + V4 e (iv) tratamentos com aplicação de CoMo em V4 vs tratamentos com aplicação de CoMo em TS + V4. Os testes estatísticos foram todos aplicados com 5\% de probabilidade de erro.

Tabela 1. Descrição dos tratamentos aplicados contendo cobalto e molibdênio, com as respectivas doses e formas de aplicação.

\begin{tabular}{lcc}
\hline Tratamentos & DOSE & Forma de Aplicação* \\
\hline (i) testemunha - sem aplicação & --- & -- \\
(ii) Cobalto 1,7\%, e Molibdênio 17\% (Speedylux) & $80 \mathrm{~mL}$ & TS \\
(iii) Cobalto 1,7\%, e Molibdênio 17\% (Speedylux) & $100 \mathrm{~mL}$ & TS \\
(iv) Cobalto 1,7\%, e Molibdênio 17\% (Speedylux) & $80 \mathrm{ml}+80 \mathrm{ml}$ & $\mathrm{TS}+\mathrm{V} 4$ \\
(v) Cobalto $1,2 \%$, e Molibdênio 12\% (Bioflash CoMo) & $100 \mathrm{ml}$ & $\mathrm{V} 4$ \\
(vi) Cobalto 1,2\%, e Molibdênio 12\% (Bioflash CoMo) & $100 \mathrm{ml}+100 \mathrm{ml}$ & $\mathrm{TS}+\mathrm{V} 4$ \\
(vii) Cobalto $1,0 \%$, e Molibdênio $12,5 \%$ (Wuxal CoMo) & $80 \mathrm{ml}$ & $\mathrm{V} 4$ \\
(viii) Cobalto $1,0 \%$, e Molibdênio 12,5\% (Wuxal CoMo) & $80 \mathrm{ml}+80 \mathrm{ml}$ & $\mathrm{TS}+\mathrm{V} 4$ \\
\hline
\end{tabular}

*TS: tratamento de sementes; V4: estádio vegetativo com três folhas trifoliadas completamente desenvolvidas.

Fonte: Elaboração dos autores.

\section{Resultados e Discussão}

Nas avaliações referentes à nodulação de plantas (Tabela 2) observou-se resposta positiva da aplicação de cobalto e molibdênio, evidenciandose um incremento no número de nódulos de aproximadamente 63, 65 e 79\% entre o melhor tratamento e a testemunha, nas avaliações realizadas aos 29, 51 e 87 dias após a emergência, respectivamente. Esses resultados confirmam os obtidos por Toledo et al. (2010), que também verificaram acréscimo no número de nódulos com a aplicação de molibdênio. Da mesma forma, Ahmed e Evans (1960) observaram efeito positivo da adição de cobalto na nodulação e na absorção de nitrogênio pela soja cultivada em solução nutritiva. Campos e Gnatta (2006), avaliando diferentes doses de Co e
Mo, também obtiveram diferença significativa entre os tratamentos na avaliação de número de nódulos por planta. Por outro lado, em trabalho realizado por Marcondes e Caires (2005), a aplicação de molibdênio e cobalto na semente cultivada em solo com pH $\left(\mathrm{CaCl}_{2}\right.$ 0,01 mol L-1 $)$ 5,2 não influenciou na nodulação das plantas de soja. Possivelmente, nesse estudo, as necessidades da cultura tenham sido supridas com as reservas do solo, não respondendo a aplicação desses nutrientes. A ausência de resposta à adição de Mo e Co também pode ser explicada pelas observações de Lantmann (2002), que verificaram maiores respostas à aplicação de molibdênio em condições de $\mathrm{pH}$ em $\mathrm{CaCl}_{2}$ menor que 4,3, para o Latossolo Roxo álico, e menor que 4,8, para o Latossolo Vermelho Escuro Álico. 
Tabela 2. Número de plantas emergidas aos 14 dias após emergência da cultura e número de nódulos presentes nas raízes de 10 plantas, aos 29, 51 e 87 dias após a emergência, em função da aplicação de Co e Mo, quadrado médio do erro (QME), estimativa da variância de um contraste estimado $(\hat{\mathrm{V}}(\hat{\mathrm{X}}))$, estatística F tabelado ( $\alpha$; Gltra; Gle), estatística D do teste de Scheffé, estimativa da média do contraste $(\hat{\mathrm{X}})$.

\begin{tabular}{|c|c|c|c|c|c|c|}
\hline \multirow{2}{*}{ Tratamento } & \multirow{2}{*}{ DOSE } & \multirow{2}{*}{ Aplicação } & \multirow{2}{*}{$\begin{array}{c}\text { População } \\
\text { de plantas } \\
\text { (número de pl m } \text { m }^{-1}\end{array}$} & \multicolumn{3}{|c|}{$\begin{array}{l}\mathrm{N}^{\circ} \text { de nódulos por planta } \\
\text { Dias após a emergência }\end{array}$} \\
\hline & & & & 29 & 51 & 87 \\
\hline Testemunha & --- & --- & 19,30 & 14,35 bc\#* & $20,40 \mathrm{ab}$ & $24,32 \mathrm{bcd}$ \\
\hline Co $1,7 \%+$ Mo $17 \%$ & $80 \mathrm{ml}$ & TS & 17,05 & $20,55 \mathrm{ab}$ & $28,00 \mathrm{ab}$ & $25,27 \mathrm{abcd}$ \\
\hline Co $1,7 \%+\mathrm{Mo} 17 \%$ & $100 \mathrm{ml}$ & TS & 18,32 & $22,87 \mathrm{a}$ & $27,17 \mathrm{ab}$ & $27,95 \mathrm{abc}$ \\
\hline Co $1,7 \%+$ Mo $17 \%$ & $80 \mathrm{ml}+80 \mathrm{ml}$ & $\mathrm{TS}+\mathrm{V} 4$ & 18,97 & $20,70 \mathrm{ab}$ & $28,35 \mathrm{ab}$ & $29,57 \mathrm{abc}$ \\
\hline Co $1,2 \%+$ Mo12\% & $100 \mathrm{ml}$ & V4 & 19,80 & $15,92 \mathrm{bc}$ & $19,85 \mathrm{~b}$ & $30,90 \mathrm{a}$ \\
\hline Co $1,2 \%+$ Mo $12 \%$ & $100 \mathrm{ml}++100 \mathrm{ml}$ & $\mathrm{TS}+\mathrm{V} 4$ & 17,62 & $18,50 \mathrm{abc}$ & $31,10 \mathrm{a}$ & $30,75 \mathrm{ab}$ \\
\hline Co $1,0 \%+$ Mo12,5\% & $80 \mathrm{ml}$ & V4 & 18,77 & $16,27 \mathrm{abc}$ & $22,92 \mathrm{ab}$ & $20,37 \mathrm{~d}$ \\
\hline Co $1,0 \%+$ Mo12,5\% & $80 \mathrm{ml}+80 \mathrm{ml}$ & $\mathrm{TS}+\mathrm{V} 4$ & 15,55 & $13,75 \mathrm{c}$ & $25,62 \mathrm{ab}$ & $23,35 \mathrm{~cd}$ \\
\hline \multicolumn{3}{|l|}{ Média } & 18,69 & 17,86 & 25,42 & 26,56 \\
\hline \multicolumn{3}{|l|}{ CV (\%) } & 8,32 & 7,73 & 8,96 & 5,21 \\
\hline \multicolumn{3}{|l|}{ QME } & 2,4180 & 1,9060 & 5,1876 & 1,9148 \\
\hline \multicolumn{3}{|l|}{$\hat{\mathrm{V}}(\hat{\mathrm{X}})$} & 25,3895 & 20,0130 & 54,4699 & 20,1058 \\
\hline \multicolumn{3}{|l|}{$\mathrm{F}$} & 2,4876 & 2,4876 & 2,4876 & 2,4876 \\
\hline \multicolumn{3}{|l|}{$\mathrm{D}$} & 33,16 & 29,44 & 48,57 & 29,51 \\
\hline \multicolumn{3}{|c|}{$\hat{\mathrm{X}}$} & $-106,78^{*}$ & $-114,21 *$ & $-162,61 *$ & $-163,84 *$ \\
\hline \multicolumn{3}{|c|}{ Testemunha (sem Co + Mo) } & 19,3 & 14,35 & 20,4 & 24,32 \\
\hline \multicolumn{3}{|c|}{ Aplicação de Co + Mo } & 18,01 & 18,37 & 26,14 & 26,88 \\
\hline \multicolumn{3}{|l|}{$\hat{V}(\hat{X})$} & 1,2090 & 0,9530 & 2,5938 & 0,9574 \\
\hline \multirow{2}{*}{\multicolumn{3}{|c|}{$\begin{array}{l}\mathrm{F} \\
\mathrm{D}\end{array}$}} & 2,4876 & 2,4876 & 2,4876 & 2,4876 \\
\hline & & & 7,24 & 6,42 & 10,60 & 6,44 \\
\hline \multicolumn{3}{|l|}{$\hat{\mathrm{X}}$} & $-3,20 \mathrm{~ns}$ & $11,23 *$ & $12,40 *$ & $1,95 \mathrm{~ns}$ \\
\hline \multicolumn{3}{|l|}{ TS } & 17,685 & 21,71 & 27,585 & 26,61 \\
\hline \multicolumn{3}{|l|}{ V4 } & 19,285 & 16,095 & 21,385 & 25,635 \\
\hline \multicolumn{3}{|l|}{$\hat{\mathrm{V}}(\hat{\mathrm{X}})$} & 14,5083 & 11,4360 & 31,1256 & 11,4890 \\
\hline \multicolumn{3}{|l|}{$\mathrm{F}$} & 2,4876 & 2,4876 & 2,4876 & 2,4876 \\
\hline \multicolumn{3}{|l|}{$\mathrm{D}$} & 25,07 & 22,26 & 36,72 & 22,31 \\
\hline \multicolumn{3}{|l|}{$\hat{\mathrm{X}}$} & $-16,77 \mathrm{~ns}$ & $-9,53 \mathrm{~ns}$ & $-29,90 \mathrm{~ns}$ & $-30,45^{*}$ \\
\hline \multicolumn{3}{|l|}{ TS } & 17,685 & 21,71 & 27,585 & 26,61 \\
\hline \multicolumn{3}{|l|}{$\mathrm{TS}+\mathrm{V} 4$} & 17,38 & 17,65 & 28,36 & 27,89 \\
\hline \multicolumn{3}{|l|}{$\hat{\mathrm{V}}(\hat{\mathrm{X}})$} & 14,5083 & 11,4360 & 31,1256 & 11,4890 \\
\hline \multicolumn{3}{|l|}{$\mathrm{F}$} & 2,4876 & 2,4876 & 2,4876 & 2,4876 \\
\hline $\mathrm{D}$ & & & 25,07 & 22,26 & 36,72 & 22,31 \\
\hline$\hat{\mathrm{X}}$ & & & $-13,57 \mathrm{~ns}$ & $-20,76 \mathrm{~ns}$ & $-42,30 *$ & $-32,40^{*}$ \\
\hline V4 & & & 19,29 & 16,10 & 21,39 & 25,64 \\
\hline $\mathrm{TS}+\mathrm{V} 4$ & & & 17,38 & 17,65 & 28,36 & 27,89 \\
\hline
\end{tabular}

\# médias não seguidas pela mesma letra diferem a 5\% de probabilidade pelo teste de Tukey;

* e ns: contrastes significativos e não significativos, respectivamente, pelo teste de Scheffé a 5\% de probabilidade.

Fonte: Elaboração dos autores. 
Ao se considerar a forma de aplicação (teste Scheffé, Tabela 2), verificou-se que o número de nódulos (29, 51 e 87 dias de avaliação) difere $(p<5 \%)$, quando se considera a aplicação de Co e Mo, independente da concentração aplicada e da forma de aplicação em relação à testemunha (sem aplicação). Além disso, essa aplicação via TS é favorável para o número de nódulos aos 29 e 51 dias em relação ao aplicado via foliar em V4. Ao comparar-se a aplicação em TS ou em TS + V4, a maior produção de nódulos ocorre, na segunda opção, evidentemente pela maior disponibilização de Co e Mo em fases distintas, permitindo um maior desenvolvimento de nódulos aos 51 e 87 dias. A mesma tendência seguiu ao comparar-se a aplicação em V4 vs TS + V4.

Com base nesses resultados é possível constatar que a aplicação de cobalto e molibdênio tem proporcionado influência significativa no processo de nodulação para a soja cultivada em condições de campo. No entanto, nos solos com alto teor de matéria orgânica, com alta fertilidade e em solos cuja acidez foi corrigida, a expectativa de resposta ao molibdênio e ao cobalto na nodulação da soja é menor (MESCHEDE et al., 2004).

Conforme apresentado na Tabela 3, todos os tratamentos foram similares em relação à testemunha para a produção de matéria seca da parte aérea e matéria seca de raiz, nos três momentos de avaliação. A matéria seca da parte aérea e de raiz foram influenciadas pela aplicação de Co e Mo, considerando-se a forma de aplicação (TS, V4 ou TS+V4), indicando-se assim que a aplicação de Co e Mo faz com que a massa seca de parte aérea e de raízes (51 e 87 dias) seja maior em relação a testemunha (sem aplicação). Porém, isso não ocorreu nas avaliações dos 29 dias, onde se percebe uma inibição da produção da massa seca (parte aérea e raízes) nos tratamentos com Co e Mo, que nas avaliações seguintes é superada. Quanto ao contraste a respeito da aplicação em TS ou em V4, verifica-se que esse não apresentou diferença significativa para as características de massa seca de parte aérea ou raízes. Porém, a massa seca da parte aérea tende a ser maior quando se realiza as aplicações de Co e Mo em TS+V4, tanto em relação à aplicação única em TS ou V4.

Leite et al. (2009), em experimento realizado com doses de Mo (0; 30; 60; 90 e $\left.120 \mathrm{~g} \mathrm{ha}^{-1}\right)$, observaram que não houve efeito do molibdênio sobre as massa das raízes na cultura do feijoeiro, no entanto a massa da parte aérea, acúmulo de $\mathrm{N}$ e a produtividade de grãos mostraram respostas significativas às doses de Mo.

Foi observado efeito significativo da adubação mineral com molibdênio e cobalto no número de vagens por planta (Tabela 4), confirmando os resultados obtidos por Andrade et al. (2001), que observaram aumentos médios de 55\% e $6 \%$ no número de vagens por planta e o número de grãos por vagem, respectivamente, com aplicação de Mo no feijoeiro. O número de grãos foi superior no tratamento onde foi aplicado $100 \mathrm{~mL}$ via tratamento de sementes $+100 \mathrm{~mL}$ via foliar no estádio V4, do fertilizante contendo $1,2 \%$ de cobalto e $12 \%$ de molibdênio (Bioflash CoMo) não diferindo da utilização de $80 \mathrm{~mL}$ no tratamento de sementes +80 $\mathrm{mL}$ via foliar no estádio $\mathrm{V} 4$, do produto comercial contendo $1,7 \%$ de cobalto e $17 \%$ de molibdênio (Wuxal CoMo) (Tabela 4). 
Tabela 3. Massa seca da parte aérea e de raízes de soja (gramas) aos 29, 51 e 87 dias após a emergência da cultura (DAE) em função da aplicação de Co e Mo, quadrado médio do erro (QME), estimativa da variância de um contraste estimado $(\hat{\mathrm{V}}(\hat{\mathrm{X}}))$, estatística $\mathrm{F}$ tabelado $(\alpha$; Gltra; Gle), estatística D do teste de Scheffé, estimativa da média do contraste $(\hat{X})$.

\begin{tabular}{|c|c|c|c|c|c|c|c|c|}
\hline \multirow[t]{2}{*}{ Tratamento } & \multirow{2}{*}{ DOSE } & \multirow[t]{2}{*}{ Aplicação } & \multicolumn{3}{|c|}{$\begin{array}{c}\text { Massa seca da parte aérea/ } \\
\text { planta } \\
\text { Dias após a emergência }\end{array}$} & \multicolumn{3}{|c|}{$\begin{array}{c}\text { Massa seca de raiz/planta } \\
\text { Dias após a emergência }\end{array}$} \\
\hline & & & 29 & 51 & 87 & 29 & 51 & 87 \\
\hline Testemunha & --- & $\begin{array}{ll}-- \\
\end{array}$ & 2,90abc\# & 9,25 & $26,07 \mathrm{ab}$ & 0,33 & $1,04 \mathrm{~b}$ & $2,57 \mathrm{ab}$ \\
\hline Co $1,7 \%+$ Mo $17 \%$ & $80 \mathrm{~mL}$ & TS & $3,25 \mathrm{a}$ & 10,35 & $26,80 \mathrm{ab}$ & 0,39 & $1,40 \mathrm{ab}$ & $2,73 \mathrm{ab}$ \\
\hline Co $1,7 \%+$ Mo $17 \%$ & $100 \mathrm{~mL}$ & TS & $2,79 \mathrm{ab}$ & 9,15 & $25,95 \mathrm{ab}$ & 0,37 & $1,21 \mathrm{ab}$ & $2,46 a b$ \\
\hline Co $1,7 \%+$ Mo $17 \%$ & $80 \mathrm{~mL}+80 \mathrm{~mL}$ & $\mathrm{TS}+\mathrm{V} 4$ & $2,99 \mathrm{ab}$ & 8,60 & $24,97 \mathrm{ab}$ & 0,35 & $1,09 \mathrm{ab}$ & $2,45 \mathrm{ab}$ \\
\hline Co $1,2 \%+$ Mo12 $\%$ & $100 \mathrm{~mL}$ & V4 & $2,85 \mathrm{abc}$ & 9,90 & $30,37 \mathrm{a}$ & 0,30 & $1,19 \mathrm{ab}$ & $2,92 \mathrm{a}$ \\
\hline Co $1,2 \%+$ Mo $12 \%$ & $100 \mathrm{~mL}+100 \mathrm{~mL}$ & $\mathrm{TS}+\mathrm{V} 4$ & $2,09 \mathrm{bc}$ & 10,60 & $29,60 \mathrm{a}$ & 0,30 & $1,46 a$ & $2,65 \mathrm{ab}$ \\
\hline Co $1,0 \%+\operatorname{Mo} 12,5 \%$ & $80 \mathrm{~mL}$ & V4 & $2,65 \mathrm{abc}$ & 9,50 & $22,62 b$ & 0,36 & $1,36 \mathrm{ab}$ & $1,83 b$ \\
\hline Co $1,0 \%+\mathrm{Mo} 12,5 \%$ & $80 \mathrm{~mL}+80 \mathrm{~mL}$ & $\mathrm{TS}+\mathrm{V} 4$ & $1,96 \mathrm{c}$ & 11,00 & $29,27 \mathrm{a}$ & 0,30 & $1,34 \mathrm{ab}$ & $2,60 \mathrm{ab}$ \\
\hline \multicolumn{3}{|l|}{ Média } & 2,68 & 9,79 & 26,95 & 0,34 & 1,26 & 2,53 \\
\hline \multicolumn{3}{|l|}{ CV (\%) } & 8,23 & 5,97 & 4,45 & 7,08 & 6,10 & 7,80 \\
\hline \multicolumn{3}{|l|}{ QME } & 0,0486 & 0,3416 & 1,4383 & 0,0006 & 0,0059 & 0,0389 \\
\hline \multicolumn{3}{|l|}{$\hat{\mathrm{V}}(\hat{\mathrm{X}})$} & 0,5108 & 3,5868 & 15,1017 & 0,0061 & 0,0620 & 0,4089 \\
\hline \multicolumn{3}{|l|}{ F } & 2,4876 & 2,4876 & 2,4876 & 2,4876 & 2,4876 & 2,4876 \\
\hline \multicolumn{3}{|c|}{$\mathrm{D}$} & 4,70 & 12,46 & 25,58 & 0,51 & 1,64 & 4,21 \\
\hline \multirow{2}{*}{\multicolumn{3}{|c|}{$\begin{array}{l}\hat{\mathrm{X}} \\
\text { Testemunha }(\mathrm{sem} \mathrm{Co}+\mathrm{Mo})\end{array}$}} & $-15,68^{*}$ & $-59,85^{*}$ & $-163,51^{*}$ & $-2,04 *$ & $-8,01^{*}$ & $-15,07 *$ \\
\hline & & & 2,9 & 9,25 & 26,07 & 0,33 & 1,04 & 2,57 \\
\hline \multicolumn{3}{|c|}{ Aplicação de Co + Mo } & 2,65 & 9,87 & 27,08 & 0,34 & 1,29 & 2,52 \\
\hline \multicolumn{3}{|l|}{$\hat{\mathrm{V}}(\hat{\mathrm{X}})$} & 0,0243 & 0,1708 & 0,7191 & 0,0003 & 0,0030 & 0,0195 \\
\hline \multicolumn{3}{|l|}{$\mathrm{F}$} & 2,4876 & 2,4876 & 2,4876 & 2,4876 & 2,4876 & 2,4876 \\
\hline \multicolumn{3}{|l|}{$\mathrm{D}$} & 1,03 & 2,72 & 5,58 & 0,11 & 0,36 & 0,92 \\
\hline \multicolumn{3}{|l|}{$\hat{\mathrm{X}}$} & $0,54 \mathrm{~ns}$ & $0,10 \mathrm{~ns}$ & $-0,24 \mathrm{~ns}$ & $0,10 \mathrm{~ns}$ & $0,06 \mathrm{~ns}$ & $0,44 \mathrm{~ns}$ \\
\hline \multicolumn{3}{|l|}{ TS } & 3,02 & 9,75 & 26,38 & 0,38 & 1,31 & 2,60 \\
\hline \multicolumn{3}{|l|}{$\mathrm{V} 4$} & 2,75 & 9,7 & 26,495 & 0,33 & 1,275 & 2,375 \\
\hline \multicolumn{3}{|l|}{$\hat{\mathrm{V}}(\hat{\mathrm{X}})$} & 0,2919 & 2,0496 & 8,6296 & 0,0035 & 0,0354 & 0,2337 \\
\hline \multicolumn{3}{|l|}{$\mathrm{F}$} & 2,4876 & 2,4876 & 2,4876 & 2,4876 & 2,4876 & 2,4876 \\
\hline \multicolumn{3}{|l|}{$\mathrm{D}$} & 3,56 & 9,42 & 19,33 & 0,39 & 1,24 & 3,18 \\
\hline \multicolumn{3}{|l|}{$\hat{\mathrm{X}}$} & $-1,00 \mathrm{~ns}$ & $-10,70^{*}$ & $-31,09^{*}$ & $-0,19 \mathrm{~ns}$ & $-1,28^{*}$ & $-2,51 \mathrm{~ns}$ \\
\hline \multicolumn{3}{|l|}{$\begin{array}{l}X \\
\text { TS }\end{array}$} & 3,02 & 9,75 & 26,375 & 0,38 & 1,305 & 2,595 \\
\hline \multicolumn{3}{|l|}{$\mathrm{TS}+\mathrm{V} 4$} & 2,35 & 10,07 & 27,95 & 0,32 & 1,30 & 2,57 \\
\hline \multicolumn{3}{|l|}{$\hat{\mathrm{V}}(\hat{\mathrm{X}})$} & 0,2919 & 2,0496 & 8,6296 & 0,0035 & 0,0354 & 0,2337 \\
\hline $\mathrm{F}$ & & & 2,4876 & 2,4876 & 2,4876 & 2,4876 & 2,4876 & 2,4876 \\
\hline $\mathrm{D}$ & & & 3,56 & 9,42 & 19,33 & 0,39 & 1,24 & 3,18 \\
\hline$\hat{x}$ & & & $-1,54 \mathrm{~ns}$ & $-10,80^{*}$ & $-30,85^{*}$ & $-0,29 \mathrm{~ns}$ & $-1,34^{*}$ & $-2,95 \mathrm{~ns}$ \\
\hline V4 & & & 2,75 & 9,70 & 26,50 & 0,33 & 1,28 & 2,38 \\
\hline $\mathrm{TS}+\mathrm{V} 4$ & & & 2,35 & 10,07 & 27,95 & 0,32 & 1,30 & 2,57 \\
\hline
\end{tabular}

\# médias não seguidas pela mesma letra diferem a 5\% de probabilidade pelo teste de Tukey;

* e ns: contrastes significativos e não significativos, respectivamente, pelo teste de Scheffé a 5\% de probabilidade.

Fonte: Elaboração dos autores. 
Em trabalho realizado por Kusdra e Ronzeli Júnior (2003) avaliando os efeitos isolados e combinados do molibdênio e o cobalto na soja, os autores observaram que o molibdênio aumentou a quantidade de nitrogênio na parte aérea, assim como o número de vagens, número de grãos e a massa de grãos, apresentando grande potencial para aumentar o rendimento da cultura. Já o cobalto teve maior influencia somente no aumento da massa de 100 grãos. Silva et al. (2011) também observaram que a aplicação de Co e Mo na soja aumentou significativamente a massa de 100 grãos, independente da forma de aplicação, se foliar ou via semente.

No que diz respeito às características do número de vagens por planta, número de grãos, massa de mil grãos e produção de grãos, percebe-se pelos contrastes testados, que a aplicação de Co e Mo, produzem médias superiores em relação as parcelas não aplicadas. Além disso, a aplicação por meio do tratamento de sementes ou via foliar em V4, não apresenta diferenças entre si, para essas quatro características. Porém, a aplicação no TS e via foliar em V4 (TS+V4) apresentou os melhores resultados para as características de número de vagens, número de grãos e produção de grãos.

Verificou-se também que houve respostas na produção de grãos da soja à aplicação de Mo e Co (Tabela 4), com aumentos de $240 \mathrm{~kg} \mathrm{ha}^{-1}$ (9,76\%) entre o melhor tratamento e a testemunha, sendo observados acréscimos em todos os tratamentos aplicados. Vitti et al. (1984) obtiveram aumentos de até $32,7 \%$ com a utilização de doses crescentes de 0 , $100,200,300$ e $400 \mathrm{~g} \mathrm{ha}^{-1}$ de produto comercial com $10 \%$ de molibdênio e $1 \%$ de cobalto em aplicação foliar. Sfredo e Oliveira (2010), em experimentos realizados em vários anos e locais do Brasil, verificaram que a aplicação de Co e Mo influenciou positivamente no rendimento de grãos da soja, com incrementos médios de aproximadamente $20 \%$ em relação à testemunha.

A forma de aplicação não apresentou diferença significativa na produtividade de grãos entre os tratamentos, ou seja, a aplicação foliar (V4) foi tão eficiente quanto a aplicação via semente (TS), mas se considerarmos os parâmetros número de grãos por vagem e número de grãos por planta pode-se detectar melhor eficiência com a aplicação nos dois estágios, ou seja, no TS e V4 juntos (Tabela 4). Embora estes parâmetros não tenham afetado a produtividade de grãos no presente ano, podem ser importantes fatores de influência em anos seguintes.

Da mesma forma, em trabalho realizado por Amane et al. (1999) a adubação com Mo aumentou a produtividade, levando a rendimentos máximos em doses que variaram de 70 a $100 \mathrm{~g} \mathrm{ha}^{-1}$. Da mesma forma, Andrade et al. (2001), obtiveram acréscimos de produtividade na ordem de $91 \%$ na cultura do feijoeiro. Binneck, Barros e Vahl(1999), trabalhando com sementes de trevo branco, observaram que o Mo propiciou incrementos na fixação de $\mathrm{N}_{2}$ e no desempenho produtivo da cultura, com aumentos na produção de forragens e de sementes. Leite et al. (2009), avaliando o efeito do fornecimento de molibdênio sobre a produtividade de feijão-caupi, observaram que o rendimento de grãos foi maior com aplicação de Mo, com um valor máximo estimado para a produtividade de grãos de $799 \mathrm{~kg}$ $\mathrm{ha}^{-1}$ na dose estimada de $63 \mathrm{~g} \mathrm{ha}^{-1}$. 
Tabela 4. Número de vagens e número de grãos da soja por planta, massa de mil grãos (MMG, g) e Produção de grãos (PG, $\mathrm{kg} \mathrm{ha}^{-1}$ ), em função da aplicação de Co e Mo, quadrado médio do erro (QME), estimativa da variância de um contraste estimado $(\hat{\mathrm{V}}(\hat{\mathrm{X}}))$, estatística F tabelado ( $\alpha$; Gltra; Gle), estatística D do teste de Scheffé, estimativa da média do contraste $(\hat{\mathrm{X}})$.

\begin{tabular}{|c|c|c|c|c|c|c|}
\hline Tratamento & DOSE & Aplicação & $\begin{array}{c}\mathrm{N}^{\circ} \text { de vagens } \\
\text { por planta } \\
126 \mathrm{DAE}\end{array}$ & $\begin{array}{c}\mathrm{N}^{\circ} \text { de grãos } \\
\text { por planta } \\
149 \text { DAE }\end{array}$ & $\begin{array}{c}\text { MMG } \\
(\mathrm{g})\end{array}$ & $\begin{array}{c}\text { PG } \\
\left(\mathrm{kg} \mathrm{ha}^{-1}\right)\end{array}$ \\
\hline Testemunha & --- & --- & $4,43 \mathrm{c \# *}$ & $8,55 \mathrm{~b}$ & 133,05 & 2.460 c $(---)^{1}$ \\
\hline Co $1,7 \%+$ Mo $17 \%$ & $80 \mathrm{~mL}$ & TS & $5,00 \mathrm{bc}$ & $8,40 \mathrm{~b}$ & 133,57 & $2.562 \mathrm{bc}(4,15)$ \\
\hline Co $1,7 \%+$ Mo17\% & $100 \mathrm{~mL}$ & TS & $4,74 \mathrm{bc}$ & $8,45 \mathrm{~b}$ & 133,35 & 2.694 a $(9,51)$ \\
\hline Co $1,7 \%+$ Mo17\% & $80 \mathrm{~mL}+80 \mathrm{~mL}$ & $\mathrm{TS}+\mathrm{V} 4$ & $4,79 \mathrm{bc}$ & $8,61 \mathrm{~b}$ & 133,42 & $2.628 \mathrm{ab}(6,83)$ \\
\hline Co $1,2 \%+$ Mo $12 \%$ & $100 \mathrm{~mL}$ & V4 & $4,86 \mathrm{bc}$ & $9,17 \mathrm{~b}$ & 135,92 & $2.700 \mathrm{a}(9,76)$ \\
\hline Co $1,2 \%+$ Mo12\% & $100 \mathrm{~mL}+100 \mathrm{~mL}$ & $\mathrm{TS}+\mathrm{V} 4$ & $6,35 \mathrm{a}$ & $12,62 \mathrm{a}$ & 132,02 & 2.696 a $(9,59)$ \\
\hline Co $1,0 \%+$ Mo12,5\% & $80 \mathrm{~mL}$ & V4 & $5,09 \mathrm{~b}$ & $9,18 \mathrm{~b}$ & 132,72 & $2.616 \mathrm{ab}(6,34)$ \\
\hline Co $1,0 \%+$ Mo $12,5 \%$ & $80 \mathrm{~mL}+80 \mathrm{~mL}$ & $\mathrm{TS}+\mathrm{V} 4$ & $5,98 \mathrm{a}$ & $10,97 \mathrm{ab}$ & 136,9 & $2.674 \mathrm{a}(8,70)$ \\
\hline Média & & & 5,15 & 9,49 & 133,87 & $2.628,80$ \\
\hline CV $(\%)$ & & & 2,44 & 6,14 & 2,07 & 2,73 \\
\hline QME & & & 0,0158 & 0,3395 & 7,6790 & 5150,3932 \\
\hline$\hat{\mathrm{V}}(\hat{\mathrm{X}})$ & & & 0,1658 & 3,5650 & 80,6300 & 54079,1286 \\
\hline $\mathrm{F}$ & & & 2,4876 & 2,4876 & 2,4876 & 2,4876 \\
\hline $\mathrm{D}$ & & & 2,68 & 12,43 & 59,10 & 1530,53 \\
\hline$\hat{\mathrm{x}}$ & & & $-32,38^{*}$ & $-58,85^{*}$ & $-804,85^{*}$ & $-16110,00^{*}$ \\
\hline Testemunha (sem Co + Mo) & & & 4,43 & 8,55 & 133,05 & $2.460,00$ \\
\hline Aplicação de Co + Mo & & & 5,26 & 9,63 & 133,99 & $2.652,86$ \\
\hline$\hat{\mathrm{V}}(\hat{\mathrm{X}})$ & & & 0,0079 & 0,1698 & 3,8395 & 2575,1966 \\
\hline $\mathrm{F}$ & & & 2,4876 & 2,4876 & 2,4876 & 2,4876 \\
\hline D & & & 0,58 & 2,71 & 12,90 & 333,99 \\
\hline$\hat{X}$ & & & $-0,21 \mathrm{~ns}$ & $-1,50 \mathrm{~ns}$ & $-1,72 \mathrm{~ns}$ & $-60,00 \mathrm{~ns}$ \\
\hline TS & & & 4,87 & 8,43 & 133,46 & $2.628,00$ \\
\hline V4 & & & 4,98 & 9,18 & 134,32 & $2.658,00$ \\
\hline$\hat{\mathrm{V}}(\hat{\mathrm{X}})$ & & & 0,0947 & 2,0371 & 46,0743 & 30902,3592 \\
\hline $\mathrm{F}$ & & & 2,4876 & 2,4876 & 2,4876 & 2,4876 \\
\hline D & & & 2,03 & 9,39 & 44,67 & 1156,97 \\
\hline$\hat{\mathrm{X}}$ & & & $-7,38^{*}$ & $-15,35^{*}$ & $-135,42 *$ & $-2742,00^{*}$ \\
\hline TS & & & 4,87 & 8,425 & 133,46 & $2.628,00$ \\
\hline $\mathrm{TS}+\mathrm{V} 4$ & & & 5,71 & 10,74 & 134,11 & $2.666,00$ \\
\hline$\hat{\mathrm{V}}(\hat{\mathrm{X}})$ & & & 0,0947 & 2,0371 & 46,07 & 30902,36 \\
\hline $\mathrm{F}$ & & & 2,4876 & 2,4876 & 2,4876 & 2,4876 \\
\hline D & & & 2,03 & 9,39 & 44,67 & $1.156,97$ \\
\hline$\hat{\mathrm{X}}$ & & & $-7,17 *$ & $-13,85^{*}$ & $-133,70^{*}$ & $-2.682,00^{*}$ \\
\hline V4 & & & 4,98 & 9,18 & 134,32 & $2.658,00$ \\
\hline $\mathrm{TS}+\mathrm{V} 4$ & & & 5,71 & 10,73 & 134,11 & $2.666,00$ \\
\hline
\end{tabular}

\# médias não seguidas pela mesma letra diferem a $5 \%$ de probabilidade pelo teste de Tukey;

* e ns: contrastes significativos e não significativos, respectivamente, pelo teste de Scheffé a 5\% de probabilidade.

${ }^{1}$ valores entre parênteses representam a percentagem de aumento da produção de grãos em relação a testemunha.

Fonte: Elaboração dos autores. 
Em trabalho realizado por Gris, Castro e Oliveira (2005), mesmo não ocorrendo efeitos significativos com a aplicação de Mo, a produtividade da soja aumentou de $2.219 \mathrm{~kg} \mathrm{ha}^{-1}$ no tratamento testemunha, para $2.413 \mathrm{~kg} \mathrm{ha}^{-1}$ com a aplicação de $40 \mathrm{~g} \mathrm{ha}^{-1} \mathrm{de}$ Mo via peletização das sementes, e para $2.415 \mathrm{~kg}$ $\mathrm{ha}^{-1}$ com a adubação foliar de $80 \mathrm{~g} \mathrm{ha}^{-1}$ de Mo. Por outro lado, Pessoa et al. (1999) não observaram efeito significativo da aplicação foliar de doses crescentes de $\mathrm{Mo}\left(0,40,80\right.$ e $\left.160 \mathrm{~g} \mathrm{ha}^{-1}\right)$ na cultura da soja, embora tenha ocorrido um incremento de $17,4 \%$ em relação à testemunha para a dose de $80 \mathrm{~g}$ $\mathrm{ha}^{-1}$. Provavelmente o teor de molibdênio no solo foi suficiente para suprir as necessidades da cultura, em função do solo utilizado ser de origem basáltica e a acidez ter sido corrigida com aplicação de calcário.

No presente trabalho não foi detectada diferença na aplicação via semente (TS) ou via foliar (V4), sendo que a conjugação dos dois meios parece ser uma alternativa viável para o melhor aproveitamento do Co e Mo pela cultura da soja, embora trabalhos como de Silva et al. (2011), com informação de vários artigos e literatura, relatam que a soja não tem respondido a aplicação de Co e Mo, independente da forma de aplicação, se foliar ou via semente.

\section{Conclusão}

A aplicação de molibdênio e cobalto via sementes e/ou foliar no estádio V4 promoveram incrementos significativos no rendimento da soja, com aumentos de até $240 \mathrm{~kg} \mathrm{ha}^{-1}$ na produção de grãos da cultura. Os parametros agronômicos avaliados foram afetados positivamente pela aplicação de Co e Mo, principalmente quando aplicado tanto via semente como foliar (TS + V4), inclusive para a produtividade de grãos. A forma de aplicação não foi significativamente distinta, ou seja, tanto a aplicação via semente como via foliar foram eficientes no fornecimento destes nutrientes para a cultura da soja.

\section{Referências}

ADÁMOLI, J.; MACÊDO, J.; AZEVEDO, L. G. de; MADEIRA NETTO, J. Caracterização da região dos cerrados. In: GOEDERT, W. J. (Ed.). Solos dos cerrados: tecnologias e estratégias de manejo. Brasília: Embrapa Cerrados, p. 33-74, 1986.

AHMED, S.; EVANS, H. J. Cobalt: a micronutrient element or the growth of soybean plants under symbiotic conditions. Soil Science, Baltimore, v. 90, p. 205-210, 1960.

AMANE, M. I. V.; VIEIRA, C.; NOVAIS, R. F.; ARAÚJO, G. A. A. Adubação nitrogenada e molíbdica da cultura do feijão na zona da mata de minas gerais. Revista Brasileira de Ciência do Solo, Viçosa, MG, v. 23, n. 41, p. 643-650, 1999.

ANDRADE, M. J. B.; ALVARENGA, P. E.; SILVA, R.; CARVALHO, J. G.; JUNQUEIRA, A. D. A. Resposta do feijoeiro às adubações nitrogenada e molíbdica e a inoculação com Rhizobium tropici. Ciência Agrotécnica, Lavras, v. 25, n. 4, p. 934-940, 2001.

BALÍK, J.; PAVLÍKOVÁ, D.; TLUSTOS, P.; SÝKORA, K.; CERNÝ, J. The fluctuation of molybdenum content in oilseed rape plants after the application of nitrogen and sulphur fertilizers. Plant Soil Environ, Praha, v. 52, n. 7, p. 301-307, 2006.

BINNECK, E.; BARROS, A. C. S. A.; VAHL, L. C. Peletização e aplicação de molibdênio em sementes de trevo branco. Revista Brasileira de Sementes, Brasília, v. 21, n. 2, p. 203-207, 1999.

BRANDELERO, E. M.; PEIXOTO, C. P.; RALISCH, R. Nodulação de cultivares de soja e seus efeitos no rendimento de grãos. Semina: Ciências Agrárias, Londrina, v. 30, n. 3, p. 581-588, 2009.

CAMPO, R. J.; LANTMANN, A. F. Efeitos de micronutrientes na fixação biológica do Nitrogênio e produtividade da soja. Pesquisa Agropecuária Brasileira, Brasília, v. 33, n. 8, p. 1245-1253, 1998.

CAMPOS, B. H. C. de; GNATTA, V. Inoculantes e fertilizantes foliares na soja em área de populações estabelecidas de Bradyrhizobium sob sistema plantio direto. Revista Brasileira de Ciência do Solo, Viçosa, MG, v. 30, n. 1, p. 69-76, 2006.

CENTRO DE PESQUISAS METEOROLÓGICAS E CLIMÁTICAS APLICADAS À AGRICULTURA CEPAGRI. A classificação climática de Koeppen para o Estado de São Paulo. 2010. Disponível em: <http:// www.cpa.unicamp.br/outras-informacoes/clima-dosmunicipios-paulistas.html>. Acesso em: 18 jun. 2011. 
CERETTA, C. A.; PAVINATO, A.; PAVINATO, P. S.; MOREIRA, I. C. L.; GIROTTO, E.; TRENTIN, E. F. Micronutrientes na soja: produtividade e análise econômica. Ciência Rural, Santa Maria, v. 35, n. 3, p. 576-581, 2005.

COMPANHIA NACIONAL DE ABASTECIMENTO CONAB. Acompanhamento da safra brasileira. 2010. Disponível em: <http://www.conab.gov.br/OlalaCMS/ uploads/arquivos/10_11_10_11_28_48_boletim_ portugues_-_nov_de_2010.pdf $>$. Acesso em: 01 jun. 2011.

CRUZ, C. D. Programa genes: biometria. Viçosa: Imprensa Universitária, 2006. 480 p.

EMPRESA BRASILEIRA DE PESQUISA AGROPECUÁRIA - EMBRAPA. Centro Nacional de Pesquisa de Solos (Rio de Janeiro, RJ). Sistema brasileiro de classificação de solos. Brasília: EmbrapaSPI, Embrapa-CNPS, 1999. 412 p.

GRIS, E. P.; CASTRO, A. M. C.; OLIVEIRA, F. F. Produtividade da soja em resposta à aplicação de molibdênio e inoculação com Bradyrhizobium japonicim. Revista Brasileira de Ciência do Solo, Viçosa, MG, v. 29, n. 151-155, p. 151-155, 2005.

HUNGRIA, M.; CAMPO, R. J.; MENDES, I. C. Fixação biológica do nitrogênio na cultura da soja. Londrina: Embrapa Soja, 2001. 48 p.

KUSDRA, J. F.; RONZELLI JÚNIOR, P. Nodulação do feijoeiro e fixação biológica do nitrogênio em resposta à microbiolização das sementes e à aplicação de micronutrientes. Scientia Agrária, Curitiba, v. 4, n. 1-2, p. 81-96, 2003.

LANTMANN, A. F. Nutrição e produtividade da soja com molibdênio e cobalto. Brasília: Embrapa, 2002. (Coletânea Rumos e Debates). Disponível em: $<$ http://www.embrapa.br/imprensa/artigos/2002/ artigo.2004-12-07.2621259858/>. Acesso em: $11 \mathrm{dez}$. 2011.

LEITE, L. F. C.; ARAÚJO, A. S. F.; COSTA, C. N.; RIBEIRO, A M. B. Nodulação e produtividade de grãos do feijão-caupi em resposta ao molibdênio. Revista Ciência Agronômica, Fortaleza, v. 40, n. 4, p. 492-497, 2009.

MARCONDES, J. A. P.; CAIRES, E. F. Aplicação de molibdênio e cobalto na semente para cultivo da soja. Bragantia, Campinas, v. 64, n. 4, p. 687-694, 2005.
MENGEL, K.; KIRKBY, E. A. Principles of plant nutrition. 5. ed. Dordrecht: Kluwer Academic Publishers, $2001.849 \mathrm{p}$.

MESCHEDE, D. K.; BRACCINI, A. L.; BRACCINI, M. C. L.; SCAPIM, C. A.; SCHUAB, S. R. P. Rendimento, teor de proteínas nas sementes e características agronômicas das plantas de soja em resposta à adubação foliar e ao tratamento de sementes com molibdênio e cobalto. Acta Scientiarum Agronomy, Maringá, v. 26, n. 2, p. 139-145, 2004.

OLIVEIRA, F. A.; SFREDO, G. J.; CASTRO, C. KLEPKER, D. Fertilidade do solo e nutrição da soja. Londrina: Embrapa, 2007. (Circular técnica, 50).

PESSOA, A. C. S.; LUCHESE, E. B.; CAVALLET, L. E.; GRIS, E. P. Produtividade de soja em resposta à adubação foliar, tratamento das sementes com molibdênio e inoculação com Bradyrhizobium japonicum. Acta Scientiarum Agronomy, Maringá, v. 21, n. 3, p. 531-535, 1999.

RAIJ, B. van; CANTARELLA, H.; QUAGGIO, J. A.; FURLANI, A. M. C. (Ed.). Recomendações de adubação e calagem para o Estado de São Paulo. 2. ed. Campinas: Instituto Agronômico \& Fundação IAC, 1996. 285 p.

SFREDO, G. J.; OLIVEIRA, M. C. N. Soja: molibdênio e cobalto. Londrina: Embrapa Soja, 2010. (Documentos/ Embrapa Soja, 322).

SILVA, A. F. da; SCHONINGER, E. L.; MONTEIRO, S.; CAIONE, G.; CARVALHO, M.A.C. de; DALCHIAVON, F. C.; NOETZOLD, R. Inoculação com bradyrhizobium e formas de aplicação de cobalto e molibdênio na cultura da soja, Revista Agrarian, Dourados, v. 4, n. 12, p. 98104, 2011.

TOLEDO, M. Z.; GARCIA, R. A.; PEREIRA, M. R. R.; BOARO, C. S. F.; LIMA, G. P. P. Nodulação e atividade da nitrato redutase em função da aplicação de molibdênio em soja. Bioscience Journal, Uberlândia, v. 26, n. 6, p. 858-864, 2010.

VITTI, G. C.; FORNASIERI FILHO, D.; PEDROSO, P. A. C.; CASTRO, R. S. A. Fertilizantes com molibdênio e cobalto na cultura da soja. Revista Brasileira de Ciência do Solo, Viçosa, MG, v. 8, n. 349-352, p. 349-352, 1984. 
